You leave.

Designs of centuries

close up

behind you

with the first wind.

You will never know, or if you do it will be later, on the way home with the evening news rolled in your hand like a totem.

\title{
RETURN TO ST. CROIX
}

The customs officer

studies my photogruph, my signature.

Am I the same person?

He looks at my face

and sees

I have cried recently.

There are scars.

He asks, "Have you cried recently?"

I stare at him

through eyes which

no longer bear

resemblance to mine.

And I show him my hands

where nothing has been added

and he folds my passport

into my palm

as if nothing has changed. 